\title{
Fingerprint Voltammograms of Copper Single Crystals under Alkaline Conditions: A
} Fundamental Mechanistic Analysis

Tiwari, Aarti; Heenen, Hendrik H.; Bjørnlund, Anton Simon; Maagaard, Thomas; Cho, EunAe; Chorkendorff, Ib; Kristoffersen, Henrik H.; Chan, Karen; Horch, Sebastian

Published in:

Journal of Physical Chemistry Letters

Link to article, DOI:

10.1021/acs.jpclett.9b03728

Publication date:

2020

Document Version

Peer reviewed version

Link back to DTU Orbit

Citation (APA):

Tiwari, A., Heenen, H. H., Bjørnlund, A. S., Maagaard, T., Cho, E., Chorkendorff, I., Kristoffersen, H. H., Chan, K., \& Horch, S. (2020). Fingerprint Voltammograms of Copper Single Crystals under Alkaline Conditions: A Fundamental Mechanistic Analysis. Journal of Physical Chemistry Letters, 11, 1450-1455.

https://doi.org/10.1021/acs.jpclett.9b03728

\section{General rights}

Copyright and moral rights for the publications made accessible in the public portal are retained by the authors and/or other copyright owners and it is a condition of accessing publications that users recognise and abide by the legal requirements associated with these rights.

- Users may download and print one copy of any publication from the public portal for the purpose of private study or research.

- You may not further distribute the material or use it for any profit-making activity or commercial gain

- You may freely distribute the URL identifying the publication in the public portal 


\section{Fingerprint Voltammograms of Copper Single}

\section{Crystals under Alkaline Conditions: A Fundamental Mechanistic Analysis}

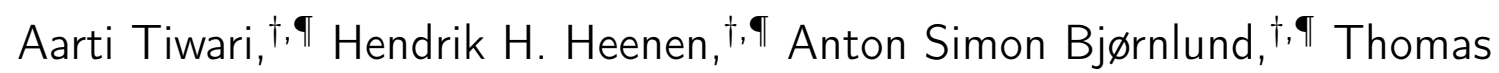
Maagaard, ${ }^{\dagger}$ EunAe Cho, ${ }^{\ddagger} \mathrm{Ib}$ Chorkendorff, ${ }^{\dagger}$ Henrik H. Kristoffersen, ${ }^{\dagger}$ Karen Chan, ${ }^{*, \dagger}$ and Sebastian Horch ${ }^{*, \dagger}$

$\dagger$ Department of Physics, Technical University of Denmark (DTU), Fysikvej 311, 2800 Kgs.

Lyngby, Denmark

$\ddagger$ Dept. of Materials Science and Engineering, KAIST, Yuseong-gu, Daejeon, 305-701, Republic of Korea

IThese authors contributed equally to this work

E-mail: kchan@fysik.dtu.dk; horch@fysik.dtu.dk 


\begin{abstract}
A critical step towards the systematic development of electrocatalysts is the determination of the microscopic structure and processes at the electrified solid/electrolyte interface. The major challenges towards this end for experiment and computations are, respectively, achieving sufficient cleanliness and modelling the complexity of electrochemical systems. In this sense, benchmarks of well-defined model systems are sparse. This work presents a rigorous joint experimental-theoretical study on the single crystal (SC) $\mathrm{Cu}$ /aqueous interface. Within typical computational uncertainties, we find quantitative agreement between simulated and experimentally measured voltammograms, which allows to unequivocally identify the ${ }^{*} \mathrm{OH}$ adsorption feature in the fingerprint region of $\mathrm{Cu}(110),(100)$ and (111) SCs under alkaline conditions. We find the inclusion of hydrogen evolution reaction kinetics in the theoretical model to be crucial for an accurate steady-state description which gives rise to a negligible $\mathrm{H}^{*}$ coverage. A purely thermodynamic description of the $\mathrm{H}^{*}$ coverage through a Pourbaix analysis would incorrectly lead to a $\mathrm{H}^{*}$ adsorption peak. The presented results establish a fundamental benchmark for all electrochemical applications of $\mathrm{Cu}$.
\end{abstract}

\title{
Graphical TOC Entry
}

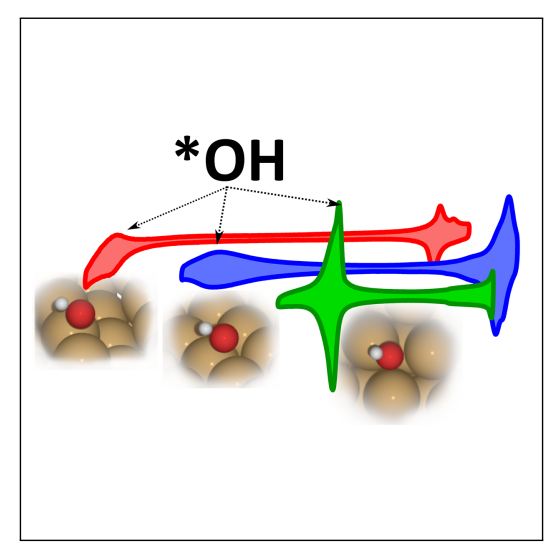




\section{Keywords}

Copper, Single Crystal, Electrocatalysis, Cyclic Voltammogram, DFT, Microkinetic modelling 
In recent years, there has been increasing interest in copper $(\mathrm{Cu})$ due to its electrocatalytic activity towards diverse applications such as nitrate reduction ${ }^{1}$ and $\mathrm{CO}_{2}$ reduction. ${ }^{2}$ The latter is heavily investigated as a possible means to store renewable electricity and to convert $\mathrm{CO}_{2}$ into valuable chemicals and fuels. Ever since the seminal work of Hori, ${ }^{3}$ much research has been devoted to elucidate why $\mathrm{Cu}$ is the only monometallic catalyst that can facilitate formation of valuable hydrocarbons and alcohols from $\mathrm{CO}_{2}$ with substantial selectivity and activity (typically in neutral or alkaline electrolytes as $\mathrm{Cu}$ is unstable in acid). The majority of these studies are done on polycrystalline, high surface area or thin film systems, whereas results on well-defined single-crystal (SC) $\mathrm{Cu}$ electrodes are sparse. Existing SC studies suggest significant variation in activity and selectivity for different $\mathrm{Cu}$ facets which -if understood- could help towards rational catalyst design e.g. by optimization of facet distribution. $^{4-6}$

To this end, a fundamental understanding is required of the electrochemical (EC) response of $\mathrm{Cu}$ SCs prior to exposure to reactant(s). In the most extensive experimental work so far, Schouten et $a l .{ }^{7}$ have investigated the structure-sensitive fingerprint region, i.e. the potential range between hydrogen evolution (HER) and the onset of irreversible $\mathrm{Cu}$ oxidation, of various $\mathrm{Cu}$ SCs in alkaline media. Their cyclic voltammograms (CV) have since been widely used both for benchmarking and deconvoluting facet distributions of various Cu catalysts. ${ }^{8-27}$ However, recently we have shown that the EC response of at least the $\mathrm{Cu}(111)$ is sensitive to contaminants dissolved from glassware in alkaline media. ${ }^{28}$ This contamination might influence peak position and shape of the CVs which is reflected in the prevailing disagreement in literature on the structure-sensitive part of the CVs of low-index Cu SCs.

The general consensus in literature is that, on bare $\mathrm{Cu}$ SCs, the peaks in the fingerprint region arise from $* \mathrm{OH}$ adsorption and desorption. This assignment has been suggested by various in-situ EC-STM studies ${ }^{29-33}$ but the inherent lack of chemical resolution in STM hampers this conclusion. In an attempt to identify the adsorbed species, Raman spectroscopy was explored but involved either glass cells or silica-covered particles and may thus 
be influenced by silicon contamination. ${ }^{34-36}$

From the theoretical perspective, ab initio simulations can give significant insight into the features of CVs. ${ }^{37,38} \mathrm{CVs}$ can be directly simulated via a thermodynamic approximation based on adsorption energies from DFT. These energies depend on the chosen atomic model of the solid/liquid interface and may be significantly affected by e.g. the way solvation effects are included. This sensitivity of results to the model system has been also found for the $\mathrm{Cu}$ $\mathrm{SC} /$ electrolyte interface, where different studies have shown widely varying $\mathrm{H}^{*}$ and ${ }^{*} \mathrm{OH}$ adsorption energies. ${ }^{27,39}$ Resulting simulated CVs deviated significantly from experimental spectra and required $a d$ hoc corrections to ab initio determined energies to achieve agreement with experimental observations. Further, some of these studies overestimate the degree of $\mathrm{H}^{*}$ adsorption. This overestimation arises from the use of a purely thermodynamic description of the adsorption processes. With the inclusion of hydrogen evolution kinetics, the steady-state $\mathrm{H}^{*}$ coverage is significantly reduced. ${ }^{40-42}$

In this joint experimental-theoretical work, we present measured benchmark CVs of clean $\mathrm{Cu}$ (110), (100) and (111) SCs and interpret them via simulated CVs. To minimize possible influences of the sample preparation, electrochemical measurements were performed on two independent sets of $\mathrm{Cu}$ SCs in two different setups, namely an ultra-high vacuum (UHV)EC setup and a conventional EC setup (details are provided in recent publications ${ }^{28,43}$ ). The SC samples for the former are pre-treated by cycles of sputter-annealing whereas the latter are electropolished (SI) before EC measurements. Figure 1 shows CVs from these two different setups using a scan rate of $50 \mathrm{mV} / \mathrm{s}$ in deaerated $0.1 \mathrm{M} \mathrm{KOH}$ electrolyte under Ar atmosphere. The basic difference is that UHV-EC measurements are on SCs without aerial exposure, while the conventional EC analysis involves a brief transfer through air between electropolishing and recording CVs. However, the EC responses after the first reductive cycle are similar for a given facet under both conditions, as seen in Figure 1.

These CVs clearly indicate that each facet has a distinct EC response. On all facets, oxidation features are observed positive of $0.25 \mathrm{~V}$ and it is the region negative of this po- 


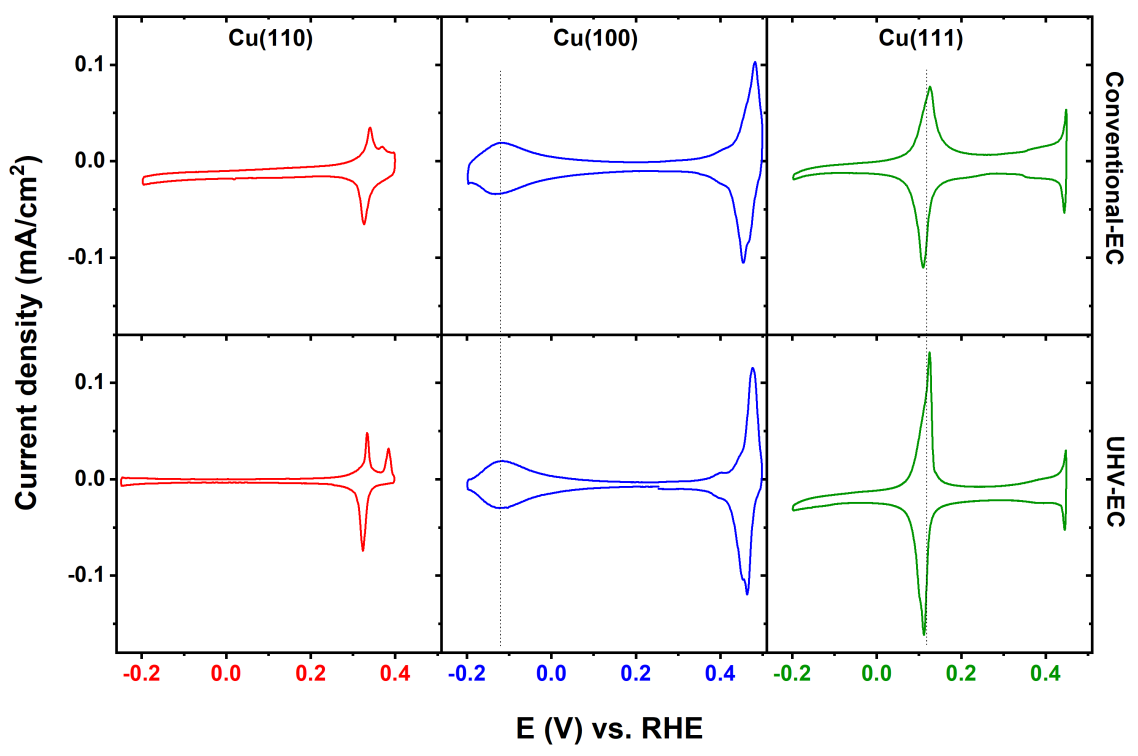

Figure 1: Cyclic voltammograms for $\mathrm{Cu}(110), \mathrm{Cu}(100)$ and $\mathrm{Cu}(111)$ in the fingerprint region measured using a conventional EC setup (top panel) and a UHV-EC setup (bottom panel) in Ar-saturated $0.1 \mathrm{M} \mathrm{KOH}$, both under Ar-atmosphere at a scan rate of $50 \mathrm{mV} / \mathrm{s}$.

tential that contains structure-sensitive information of the exposed facet. Before discussing these particular features in depth, it is important to note that the potential regions of the measurements in Figure 1 have been chosen to match those considered in recent studies. ${ }^{7}$ This choice avoids both anodic $\mathrm{Cu}$ bulk oxidation and cathodic hydrogen evolution that might influence the fingerprint features, which is the subject of an ongoing study.

Concerning the facet-specific features, $\mathrm{Cu}(111)$ exhibits a sharp redox feature at $0.12 \mathrm{~V}$ vs. RHE which can be attributed to reversible adsorption/desorption of $\mathrm{OH}$. This feature is in stark contrast to asymmetric CVs reported previously on $\mathrm{Cu}(111)$, where glass and/or $\mathrm{Si}$ was involved, which leads to multiple and asymmetric peaks. ${ }^{28} \mathrm{The} \mathrm{Cu}(100)$ exhibits a broad feature centred at $-0.13 \mathrm{~V}$ vs. RHE. Interestingly, no feature is observed in this potential window on the $\mathrm{Cu}(110)$, consistent with previous reports. ${ }^{7,18,27}$

The trend of the workfunction $(\Phi)$ for the different facets, $\Phi(110)<\Phi(100)<\Phi(111),{ }^{44}$ implies the position of the ${ }^{*} \mathrm{OH}$ feature on the (110) to be at even more negative potential, 
as the binding energy and thus the onset potential of the redox features scale with $\Phi .{ }^{45}$ Therefore, we extended the lower bound for $\mathrm{Cu}(110)$ to $-0.4 \mathrm{~V}$ even though this means that HER sets in which was avoided by the traditionally used bounds. Figure 2 shows the resulting $\mathrm{CV}$ for $\mathrm{Cu}(110)$ (top left panel) and a reversible feature is observed at $-0.34 \mathrm{~V}$ vs. RHE although convoluted with the onset of HER. Thus a clear trend of the facet-dependent reversible $\mathrm{OH}$ adsorption/desorption feature is observed.
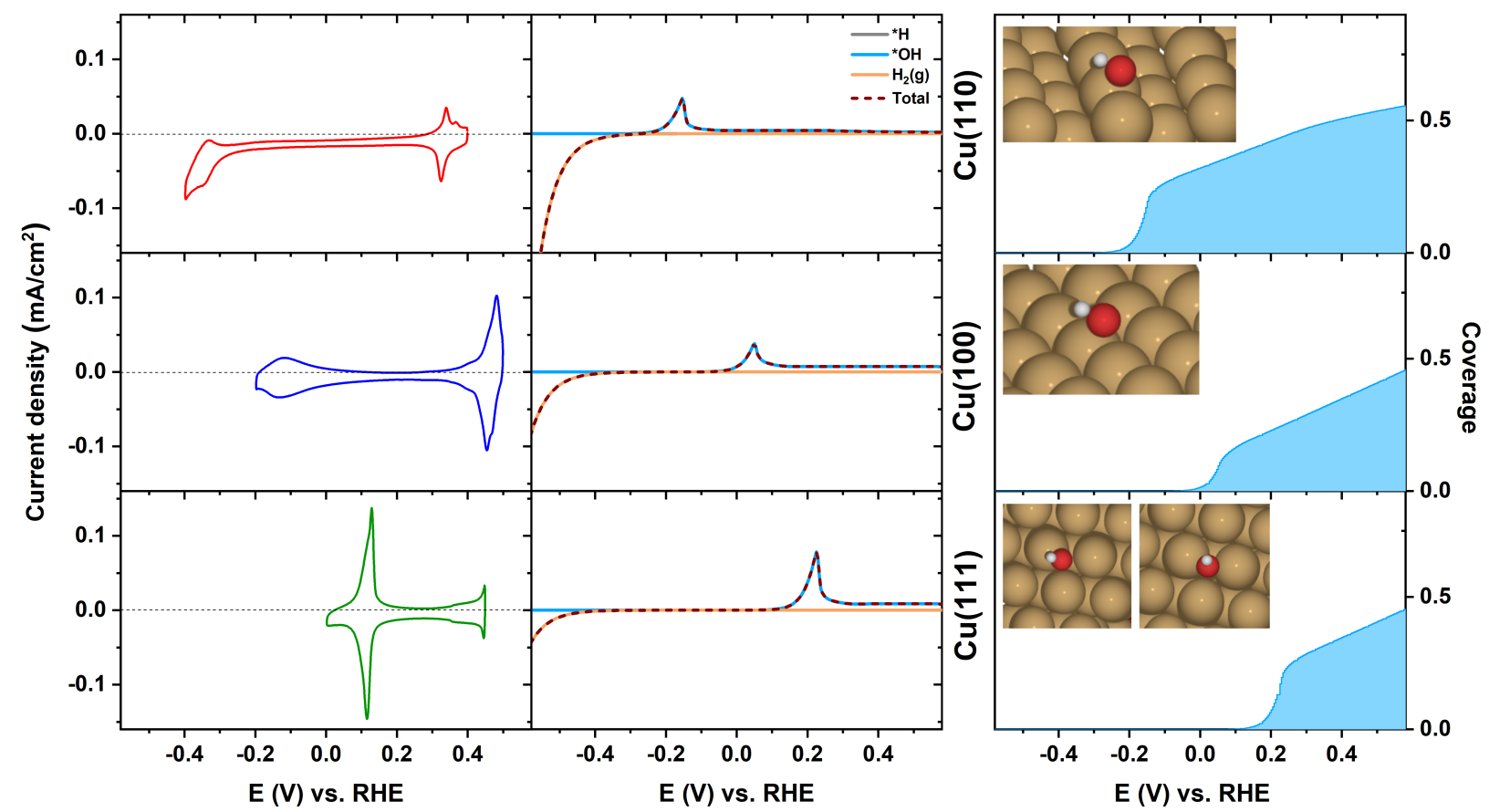

Figure 2: (Left column) Experimental CVs for $\mathrm{Cu}(110), \mathrm{Cu}(100)$ and $\mathrm{Cu}(111)$ depicting facet-dependent $\mathrm{OH}$ adsorption/desorption features in Ar-saturated 0.1 M KOH electrolyte at a scan rate of $50 \mathrm{mV} / \mathrm{s}$; (center column) Simulated CVs for a scan rate of $50 \mathrm{mV} / \mathrm{s}$, considering competing contribution from $\mathrm{H}^{*},{ }^{*} \mathrm{OH}$ and HER; and (right column) Calculated $* \mathrm{OH}$ coverage as a function of potential. Insets illustrate the optimal adsorption geometry of $\mathrm{OH}$ under these conditions.

In order to get a deeper understanding of the nature of these features, we simulate CVs using microkinetic modelling in conjunction with ab initio reaction energetics that incorporate the impact of solvent and potential. Building on previous developments, ${ }^{37,38,40}$ we unite macroscopic reaction kinetics and adsorption processes in the definition of the simulated CV. This approach allows for an accurate current/potential relationship resulting from electro- 
chemical $* \mathrm{OH}$ adsorption and the HER processes. The kinetic equations were solved with the CatMap code ${ }^{46}$ (SI Sec. IIIa). The atomic-scale elementary surface processes were modeled by DFT simulations employing the BEEF-vdW ${ }^{47}$ exchange-correlation functional. An appropriate description of the $\mathrm{Cu}$ /water interface including the adsorbates considered ${ }^{37,48}$ was obtained with the SCCS continuum solvation model in the Quantum ESPRESSO code ${ }^{49}$ and Environ package ${ }^{50,51}$ (SI Sec. II). Proton-electron transfer processes were described via the computational hydrogen-electrode. ${ }^{52}$ Adsorption sites for $\mathrm{H}^{*}$ and ${ }^{*} \mathrm{OH}$ were rigorously sampled using $\mathrm{ASE}^{53} / \mathrm{CatKit}^{54}$ and a first order ${ }^{*} \mathrm{OH}-* \mathrm{OH}$ interaction model was parameterized to include lateral interactions ${ }^{55}$ (SI Sec. IIIb). Coupled proton-electron barriers for HER were taken from previous work ${ }^{56}$ and adjusted to alkaline conditions via an empirical correction of $\approx 0.10 \mathrm{eV}$ (SI Sec. IIIc).

The simulated electrochemical processes reveal a qualitatively similar atomistic picture for all facets within the investigated potential ranges as evident in Figure 2. At very negative potentials of $\leq-0.4 \mathrm{~V}$, a steady-state HER feature is solely dominant. Since the Volmer step $\left(=\mathrm{H}^{*}\right.$ adsorption $)$ is rate limiting, it is only accompanied by marginal $\mathrm{H}^{*}$ coverage $(<$ 1\%). At more positive potentials, the HER subsides and a bare surface is exposed until * $\mathrm{OH}$ adsorption sets in. At the onset of adsorption, the surface is immediately covered by $20-30 \% * \mathrm{OH}$ at which point repulsive lateral interactions between the adsorbates become limiting. At more positive potentials, ${ }^{*} \mathrm{OH}$ surface coverage slowly increases, which results from competition between increasing potential driving force towards adsorption and the increasing lateral interactions. A coverage of $\approx 30-50 \%$ is reached when $\mathrm{Cu}$ oxidation sets in, ${ }^{57}$ which is not included in this model. The $\mathrm{Cu}$ facets differ quantitatively in the onset potentials for HER and ${ }^{*} \mathrm{OH}$ adsorption which comes from the differences in adsorption and reaction energies (compare table S1 and Figure 2).

We obtain a direct comparison to experiment through simulated CVs (Figure 2, central panel), assuming a scan rate of $50 \mathrm{mV} / \mathrm{s}$. This comparison identifies the reversible redox feature in the fingerprint region to arise from $* \mathrm{OH}$ ad-/desorption. A clear qualitative 
Table 1: Comparison of $\mathrm{OH}$ adsorption-peak charge densities $\mu \mathrm{C} / \mathrm{cm}^{2}$ for the different $\mathrm{Cu}$ facets: (Second column) expected charge density for a full $1 \mathrm{ML}$ coverage for comparison, (third column) experimental values, (fourth column) theoretical values. The measured potential of the $\mathrm{OH}$ adsorption-peak $E_{\mathrm{p}}$ [V vs. RHE] is given in the last column. The error for the experimental charge densities was estimated to $5 \mathrm{\mu C} / \mathrm{cm}^{2}$ (Estimated from the $\mathrm{OH}$ adsorption peak)

\begin{tabular}{|c|c|c|c|c|}
\hline \multirow{2}{*}{$\mathrm{Cu}$ facet } & \multicolumn{3}{|c|}{ Charge density } & \multirow[b]{2}{*}{$E_{\mathrm{p}}$} \\
\hline & $1 \mathrm{ML}$ & exp. & theory & \\
\hline$(1 \times 1)$ & 173.4 & \multirow[b]{2}{*}{25} & 54 & \multirow[b]{2}{*}{-0.34} \\
\hline$(110)-(1 \times 2)$ & 86.7 & & 27 & \\
\hline$(100)$ & 245.2 & 58 & 59 & -0.12 \\
\hline (111) & 283.2 & 78 & 79 & 0.12 \\
\hline
\end{tabular}

agreement in the shapes and positions of the ${ }^{*} \mathrm{OH}$ peaks, as well as in the HER features on the $\mathrm{Cu}(110)$ is seen (see Figure 2). The quantitative deviation between experimental and theoretical ${ }^{*} \mathrm{OH}$ adsorption peaks is found in a shift to positive potentials by $0.1-0.2 \mathrm{eV}$. This error is within the uncertainty of DFT. One qualitative difference vs. experiment is seen in the small trailing currents following the ${ }^{*} \mathrm{OH}$ adsorption peak, which result from a small and continuous increase in ${ }^{*} \mathrm{OH}$ coverage. While this phenomenon is probably present in the experimental signal, but to a negligible extent, it is likely overestimated in the simulation. This deviation may result from the idealized interaction model which neglects entropic barriers due to missing spatial resolution in the mean-field approach employed. ${ }^{58}$

In contrast to the ${ }^{*} \mathrm{OH}$ adsorption free energy defining the ${ }^{*} \mathrm{OH}$ peak position, the $\mathrm{H}^{*}$ adsorption free energy has little influence on the CV. Since the HER is limited by the Volmer step, essentially all $\mathrm{H}^{*}$ on the surface is immediately consumed to form $\mathrm{H}_{2}$ (SI Sec. IIId), which prevents a $\mathrm{H}^{*}$ adsorption peak. This behavior agrees with the present experimental data and underlines the importance of including kinetic processes into CV simulations. In the usually applied pure thermodynamic picture (which excludes HER), substantial $\mathrm{H}^{*}$ coverage is predicted from theoretical phase diagrams ${ }^{39,59}$ and simulated CVs. ${ }^{27}$ This picture would also appear in the present work if the HER processes were excluded (SI Sec. IV).

The area under the ${ }^{*} \mathrm{OH}$ adsorption peaks is proportional to the charge transferred during the adsorption processes and thus to the surface coverage. As shown in Table 1, experimental 
and theoretical charge densities for the main * $\mathrm{OH}$ adsorption peak agree. This result demonstrates an accurate description of the microscopic processes in the simulation. The transferred charge in the case of the assumed pristine $\mathrm{Cu}(110)$ suggests a $(1 \times 2)$-reconstruction because it deviates by a factor of two for the non-reconstructed $\mathrm{Cu}(110)$. Coincidentally, the reconstruction does not change peak positions and shapes of the $\mathrm{CV}$, since the atomic $* \mathrm{OH}$ adsorption site remains unaffected (SI Sec. II and III). It should be noted, however, that a clear experimental quantification of the charge density is difficult, since the ${ }^{*} \mathrm{OH}$ peak of the (110) is convoluted with the onset of HER.

In summary, we present a comprehensive study of the fingerprint CVs of Cu SCs. A facetdependent ${ }^{*} \mathrm{OH}$ feature is observed experimentally and confirmed with ab initio simulations. Thus, a clear electrochemical distinction between the facets is established. These features can be used to verify the cleanliness of samples/setups and to deconvolute the facet distribution of nanoparticles, thin-films etc. which will help future rational catalyst design. Furthermore, these results provide understanding of the fundamental EC behavior of these $\mathrm{Cu}$ facets and can serve as a starting point for investigation of the CV response in more complex situations, for instance, in the presence of reactants. From a theoretical viewpoint, we illustrate a facile way of simulating faradaic and pseudo capacitive currents in CVs using microkinetic modeling. We demonstrate that kinetics are essential for an accurate description of the $\mathrm{Cu}$ /electrolyte interface in regard of (competitive) $\mathrm{H}^{*}$ adsorption. The presented approach can be systematically extended to include more complex chemistry and simulate respective CVs.

\section{Acknowledgement}

This work was supported by research grant 9455 from VILLUM FONDEN and the European Union's Horizon 2020 research and innovation programme under the Marie Sklodowska-Curie grant agreement no. 713683 . 


\section{Supporting Information Available}

Experimental details; full details of the DFT calculations and kinetic mean-field models; methodology for simulating CV-spectra from microkinetic models; detailed discussion of the influence of HER and the atomic model for the $\mathrm{Cu} /$ electrolyte interface.

\section{References}

(1) Rosca, V.; Duca, M.; de Groot, M. T.; Koper, M. T. M. Nitrogen Cycle Electrocatalysis. Chem. Rev. 2009, 109, 2209-2244.

(2) Nitopi, S.; Bertheussen, E.; Scott, S. B.; Liu, X.; Engstfeld, A. K.; Horch, S.; Seger, B.; Stephens, I. E. L.; Chan, K.; Hahn, C. et al. Progress and Perspectives of Electrochemical CO 2 Reduction on Copper in Aqueous Electrolyte. Chem. Rev. 2019, 119, $7610-7672$.

(3) Hori, Y. In Mod. Asp. Electrochem.; Vayenas, C., White, R., Gamboa-Aldeco, M., Eds.; Springer, 2008; Vol. 42; Chapter 3, pp 89-189.

(4) Loiudice, A.; Lobaccaro, P.; Kamali, E. A.; Thao, T.; Huang, B. H.; Ager, J. W.; Buonsanti, R. Tailoring Copper Nanocrystals towards C2 Products in Electrochemical CO2 Reduction. Angew. Chemie Int. Ed. 2016, 55, 5789-5792.

(5) Iyengar, P.; Huang, J.; De Gregorio, G. L.; Gadiyar, C.; Buonsanti, R. Size dependent selectivity of $\mathrm{Cu}$ nano-octahedra catalysts for the electrochemical reduction of $\mathrm{CO} 2$ to CH 4. Chem. Commun. 2019, 55, 8796-8799.

(6) Luc, W.; Fu, X.; Shi, J.; Lv, J. J.; Jouny, M.; Ko, B. H.; Xu, Y.; Tu, Q.; Hu, X.; $\mathrm{Wu}$, J. et al. Two-dimensional copper nanosheets for electrochemical reduction of carbon monoxide to acetate. Nat. Catal. 2019, 2, 423-430. 
(7) Schouten, K. J. P.; Pérez-Gallent, E.; Koper, M. T. M. The electrochemical characterization of copper single-crystal electrodes in alkaline media. J. Electroanal. Chem. 2013, 699, 6-9.

(8) Schouten, K. J. P.; Pérez Gallent, E.; Koper, M. T. M. Structure Sensitivity of the Electrochemical Reduction of Carbon Monoxide on Copper Single Crystals. ACS Catal. 2013, 3, 1292-1295.

(9) Schouten, K. J. P.; Pérez Gallent, E.; Koper, M. T. The influence of pH on the reduction of CO and CO 2 to hydrocarbons on copper electrodes. J. Electroanal. Chem. 2014, $716,53-57$.

(10) Ledezma-Yanez, I.; Gallent, E. P.; Koper, M. T.; Calle-Vallejo, F. Structure-sensitive electroreduction of acetaldehyde to ethanol on copper and its mechanistic implications for CO and CO 2 reduction. Catal. Today 2016, 262, 90-94.

(11) Kim, Y.-G.; Javier, A.; Baricuatro, J. H.; Soriaga, M. P. Regulating the Product Distribution of $\mathrm{CO}$ Reduction by the Atomic-Level Structural Modification of the $\mathrm{Cu}$ Electrode Surface. Electrocatalysis 2016, 7, 391-399.

(12) Le Duff, C. S.; Lawrence, M. J.; Rodriguez, P. Role of the Adsorbed Oxygen Species in the Selective Electrochemical Reduction of CO 2 to Alcohols and Carbonyls on Copper Electrodes. Angew. Chemie Int. Ed. 2017, 56, 12919-12924.

(13) Pérez-Gallent, E.; Figueiredo, M. C.; Calle-Vallejo, F.; Koper, M. T. M. Spectroscopic Observation of a Hydrogenated CO Dimer Intermediate During CO Reduction on $\mathrm{Cu}(100)$ Electrodes. Angew. Chemie Int. Ed. 2017, 56, 3621-3624.

(14) Pérez-Gallent, E.; Figueiredo, M. C.; Katsounaros, I.; Koper, M. T. Electrocatalytic reduction of Nitrate on Copper single crystals in acidic and alkaline solutions. Electrochim. Acta 2017, 227, 77-84. 
(15) Pérez-Gallent, E.; Marcandalli, G.; Costa Figueiredo, M.; Calle-Vallejo, F.; T. M. Koper, M. Structure- and Potential-Dependent Cation Effects on CO Reduction at Copper Single-Crystal Electrodes. J. Am. Chem. Soc. 2017, 139, 16412-16419.

(16) Hahn, C.; Hatsukade, T.; Kim, Y.-G.; Vailionis, A.; Baricuatro, J. H.; Higgins, D. C.; Nitopi, S. A.; Soriaga, M. P.; Jaramillo, T. F. Engineering Cu surfaces for the electrocatalytic conversion of $\mathrm{CO} 2$ : Controlling selectivity toward oxygenates and hydrocarbons. Proc. Natl. Acad. Sci. 2017, 114, 5918-5923.

(17) Cao, L.; Raciti, D.; Li, C.; Livi, K. J. T.; Rottmann, P. F.; Hemker, K. J.; Mueller, T.; Wang, C. Mechanistic Insights for Low-Overpotential Electroreduction of CO 2 to CO on Copper Nanowires. ACS Catal. 2017, 7, 8578-8587.

(18) Huang, Y.; Handoko, A. D.; Hirunsit, P.; Yeo, B. S. Electrochemical Reduction of CO 2 Using Copper Single-Crystal Surfaces: Effects of CO* Coverage on the Selective Formation of Ethylene. ACS Catal. 2017, 7, 1749-1756.

(19) Resasco, J.; Chen, L. D.; Clark, E.; Tsai, C.; Hahn, C.; Jaramillo, T. F.; Chan, K.; Bell, A. T. Promoter Effects of Alkali Metal Cations on the Electrochemical Reduction of Carbon Dioxide. J. Am. Chem. Soc. 2017, 139, 11277-11287.

(20) Huang, Y.; Ong, C. W.; Yeo, B. S. Effects of Electrolyte Anions on the Reduction of Carbon Dioxide to Ethylene and Ethanol on Copper (100) and (111) Surfaces. ChemSusChem 2018, 11, 3299-3306.

(21) Garza, A. J.; Bell, A. T.; Head-Gordon, M. Mechanism of CO 2 Reduction at Copper Surfaces: Pathways to C 2 Products. ACS Catal. 2018, 8, 1490-1499.

(22) Ju, W.; Zeng, J.; Bejtka, K.; Ma, H.; Rentsch, D.; Castellino, M.; Sacco, A.; Pirri, C. F.; Battaglia, C. Sn-decorated $\mathrm{Cu}$ for selective electrochemical CO 2 to $\mathrm{CO}$ conversion: Precision architecture beyond composition design. ACS Appl. Energy Mater. 2019, 2, 867-872. 
(23) Engstfeld, A. K.; Maagaard, T.; Horch, S.; Chorkendorff, I.; Stephens, I. E. L. Polycrystalline and Single-Crystal Cu Electrodes: Influence of Experimental Conditions on the Electrochemical Properties in Alkaline Media. Chem. - A Eur. J. 2018, 24, $17743-17755$.

(24) Lum, Y.; Ager, J. W. Evidence for product-specific active sites on oxide-derived Cu catalysts for electrochemical CO2 reduction. Nat. Catal. 2019, 2, 86-93.

(25) Ju, W.; Jiang, F.; Ma, H.; Pan, Z.; Zhao, Y. B.; Pagani, F.; Rentsch, D.; Wang, J.; Battaglia, C. Electrocatalytic Reduction of Gaseous CO2 to CO on Sn/Cu-NanofiberBased Gas Diffusion Electrodes. Adv. Energy Mater. 2019, 1901514, 1-6.

(26) Sebastián-Pascual, P.; Mezzavilla, S.; Stephens, I. E. L.; Escudero-Escribano, M. Structure-Sensitivity and Electrolyte Effects in CO 2 Electroreduction: From Model Studies to Applications. ChemCatChem 2019, 11, 3626-3645.

(27) Bagger, A.; Arán-Ais, R. M.; Halldin Stenlid, J.; Campos dos Santos, E.; Arnarson, L.; Degn Jensen, K.; Escudero-Escribano, M.; Roldan Cuenya, B.; Rossmeisl, J. Ab Initio Cyclic Voltammetry on $\mathrm{Cu}(111), \mathrm{Cu}(100)$ and $\mathrm{Cu}(110)$ in Acidic, Neutral and Alkaline Solutions. ChemPhysChem 2019, 20, 3096-3105.

(28) Tiwari, A.; Maagaard, T.; Chorkendorff, I.; Horch, S. Effect of Dissolved Glassware on the Structure-Sensitive Part of the $\mathrm{Cu}(111)$ Voltammogram in KOH. ACS Energy Lett. 2019, 4, 1645-1649.

(29) Maurice, V.; Strehblow, H.-H.; Marcus, P. In situ STM study of the initial stages of oxidation of $\mathrm{Cu}(111)$ in aqueous solution. Surf. Sci. 2000, 458, 185-194.

(30) Matsumoto, T.; Bennett, R.; Stone, P.; Yamada, T.; Domen, K.; Bowker, M. Scanning tunneling microscopy studies of oxygen adsorption on $\mathrm{Cu}(111)$. Surf. Sci. 2001, 471, $225-245$. 
(31) Kunze, J.; Maurice, V.; Klein, L. H.; Strehblow, H.-H.; Marcus, P.; KunzeLiebhäuser, J.; Maurice, V.; Klein, L. H.; Strehblow, H.-H.; Marcus, P. In Situ Scanning Tunneling Microscopy Study of the Anodic Oxidation of $\mathrm{Cu}(111)$ in $0.1 \mathrm{M} \mathrm{NaOH}$. J. Phys. Chem. B 2001, 105, 4263-4269.

(32) Kunze, J.; Maurice, V.; Klein, L. H.; Strehblow, H.-H.; Marcus, P. In situ STM study of the effect of chlorides on the initial stages of anodic oxidation of $\mathrm{Cu}(111)$ in alkaline solutions. Electrochim. Acta 2003, 48, 1157-1167.

(33) Matsuoka, O.; Ono, S. S.; Nozoye, H.; Yamamoto, S. Structure and dynamics of oxyoverlayer on $\mathrm{Cu}(111)$ electrode surfaces in alkaline aqueous solution revealed by electrochemical STM and quartz crystal microbalance measurement. Surf. Sci. 2003, 545, $8-18$.

(34) Härtinger, S.; Pettinger, B.; Doblhofer, K. Cathodic formation of a hydroxide adsorbate on $\mathrm{Cu}(111)$ electrodes in alkaline electrolyte. J. Electroanal. Chem. 1995, 397, 335-338.

(35) Niaura, G. Surface-enhanced Raman spectroscopic observation of two kinds of adsorbed OH- ions at copper electrode. Electrochim. Acta 2000, 45, 3507-3519.

(36) Bodappa, N.; Su, M.; Zhao, Y.; Le, J.-B.; Yang, W.-M.; Radjenovic, P.; Dong, J.-C.; Cheng, J.; Tian, Z.-Q.; Li, J.-F. Early Stages of Electrochemical Oxidation of $\mathrm{Cu}(111)$ and Polycrystalline Cu Surfaces Revealed by in Situ Raman Spectroscopy. J. Am. Chem. Soc. 2019, 141, 12192-12196.

(37) Karlberg, G.; Jaramillo, T.; E. Skúlason, E.; Rossmeisl, J.; Bligaard, T.; Nørskov, J. Cyclic Voltammograms for H on Pt(111) and Pt(100) from First Principles. Phys. Rev. Lett. 2007, 99, 126101.

(38) Li, Y.; Janik, M. J. Recent progress on first-principles simulations of voltammograms. Curr. Opin. Electrochem. 2019, 14, 124-132. 
(39) Sandberg, R. B.; Montoya, J. H.; Chan, K.; Nørskov, J. K. CO-CO coupling on Cu facets: Coverage, strain and field effects. Surf. Sci. 2016, 654, 56-62.

(40) Jinnouchi, R.; Kodama, K.; Hatanaka, T.; Morimoto, Y. First principles based mean field model for oxygen reduction reaction. Phys. Chem. Chem. Phys. 2011, 13, 2107021083.

(41) Intikhab, S.; Snyder, J. D.; Tang, M. H. Adsorbed hydroxide does not participate in the volmer step of alkaline hydrogen electrocatalysis. ACS Catal. 2017, 7, 8314-8319.

(42) Marshall, A. T. Using microkinetic models to understand electrocatalytic reactions. Curr. Opin. Electrochem. 2018, 7, 75-80.

(43) Maagaard, T.; Tiwari, A.; Chorkendorff, I.; Horch, S. On the Possibilities and Considerations of Interfacing Ultra-High Vacuum Equipment with an Electrochemical Setup. ChemPhysChem 2019, 20, 3024-3029.

(44) Kawano, H. Effective work functions for ionic and electronic emissions from mono- and polycrystalline surfaces. Prog. Surf. Sci. 2008, 83, 1-165.

(45) Trasatti, S.; Lust, E. Modern Aspects of Electrochemistry; 1999; Vol. 33.

(46) Medford, A.; Shi, C.; Hoffmann, M.; Lausche, A.; Fitzgibbon, S.; Bligaard, T.; Nørskov, J. CatMAP: A Software Package for Descriptor-Based Microkinetic Mapping of Catalytic Trends. Catal. Lett. 2015, 145.

(47) Wellendorff, J.; Lundgaard, K. T.; Møgelhøj, A.; Petzold, V.; Landis, D. D.; Nørskov, J. K.; Bligaard, T.; Jacobsen, K. W. Density functionals for surface science: Exchange-correlation model development with Bayesian error estimation. Phys. Rev. B 2012, 85, 235149 .

(48) Heenen, H. H.; Gauthier, J.; Kristoffersen, H. H.; Ludwig, T.; Chan, K. Solvation at 
Metal/water Interfaces: An Ab Initio Molecular Dynamics Benchmark of Common Computational Approaches. ChemRxiv Preprint 2020,

(49) Giannozzi, P.; Baroni, S.; Bonini, N.; Calandra, M.; Car, R.; Cavazzoni, C.; Ceresoli, D.; Chiarotti, G. L.; Cococcioni, M.; Dabo, I. et al. QUANTUM ESPRESSO: a modular and open-source software project for quantum simulations of materials. J. Phys. Condens. Matter 2009, 21, 395502.

(50) Andreussi, O.; Dabo, I.; Marzari, N. Revised self-consistent continuum solvation in electronic-structure calculations. J. Chem. Phys. 2012, 136.

(51) Andreussi, O.; Nattino, F.; Dabo, I.; Timrov, I.; Fisicaro, G.; Goedecker, S.; Marzari, N. http: //www . quantum-environment.org.

(52) Nørskov, J.; Rossmeisl, J.; Logadottir, A.; Lindqvist, L.; Kitchin, J.; Bligaard, T.; Jónsson, H. Origin of the Overpotential for Oxygen Reduction at a Fuel-Cell Cathode. J. Phys. Chem. B 2004, 108, 17886-17892.

(53) Larsen, A. H.; Mortensen, J. J.; Blomqvist, J.; Castelli, I. E.; Christensen, R.; Dułak, M.; Friis, J.; Groves, M. N.; Hammer, B.; Hargus, C. et al. The atomic simulation environment - a Python library for working with atoms. J. Phys. Condens. Matter 2017, 29, 273002 .

(54) Boes, J. R.; Mamun, O.; Winther, K.; Bligaard, T. Graph Theory Approach to HighThroughput Surface Adsorption Structure Generation. J. Phys. Chem. A 2019, 123, $2281-2285$.

(55) Lausche, Adam C. and Medford, Andrew J. and Kahn, Tuhin Suvra and Xu, Yue and Bligaard, Thomas and Abild-Pedersen, Frank and Nørskov, Jens K. and Studt, Felix, On the effect of coverage-dependent adsorbate-adsorbate interactions for CO methanation on transition metal surfaces. J. Catal. 2013, 30\%, 275-282. 
(56) Liu, X.; Schlexer, P.; Xiao, J.; Ji, Y.; Wang, L.; Sandberg, R. B.; Tang, M.; Brown, K. S.; Peng, H.; Ringe, S. et al. pH effects on the electrochemical reduction of $\mathrm{CO}\left({ }_{2}\right)$ towards $\mathrm{C}_{2}$ products on stepped copper. Nat. Commun. 2019, 10 .

(57) Kunze-Liebhäuser, J. Encycl. Interfacial Chem.; Elsevier, 2018; pp 107-120.

(58) Andersen, M.; Panosetti, C.; Reuter, K. A Practical Guide to Surface Kinetic Monte Carlo Simulations. Fron. Chem. 2019, 7, 202.

(59) Protopopoff, E.; Marcus, P. Potential-pH diagrams for hydroxyl and hydrogen adsorbed on a copper surface. Electrochim. Acta 2005, 51, 408-417. 